\title{
ПРОФЕССИОНАЛЬНЫЕ ТРАНСФОРМАЦИИ СОТРУДНИКОВ ПЕНИТЕНЦИАРНЫХ УЧРЕЖДЕНИЙ
}

\author{
Е. Л. Трофимова \\ Байкальский государственный университет, г. Иркутск, Российская Федерациия
}

\section{ИНФОРМАЦИЯ О СТАТЬЕ}

Дата поступления 14 сентября 2016 г.

Дата принятия к печати 28 октября 2016 г.

Дата онлайн-размещения 28 декабря 2016 г.

\section{КАЮЧЕВЫЕ СКОВА}

Профессиональные трансформации, профессиональные деформации, эмоциональное выгорание, личностные ресурсы профессиональных деформаций

\begin{abstract}
АННОТАЦИЯ
Уголовно-исполнительная система, являясь элементом правоохранительной системы страны, выполняет очень важные функции, предъявляя к своим сотрудником повышенные требования. Условия профессиональной деятельности являются объективным фактором возникновения профессиональных деформаций. Одновременно, в процессе выполнения профессиональных обязанностей, приобретения опыта вырабатываются переменные, которые помогают личности снизить негативное влияние деятельности. В статье кратко обосновывается целесообразность применения термина «профессиональные трансформации», под которыми понимаются любые личностные изменения, происходящие с человеком в процессе его профессиональной деятельности. Обсуждаются результаты исследования происходящих в процессе профессиональной деятельности личностных изменений сотрудников пенитенциарных учреждений, например, изменений ценностных ориентаций, преобладающих моделей поведения, динамики профессиональной активности и др. В исследовании принимали участие сотрудники УИС с разным стажем службы: от 1 года до 3-х лет, от 4-х до 7 лет, и свыше 8 лет. Использовался комплекс стандартизированных психодиагностических методик. Полученные данные позволяют сделать выводы о том, что со стажем наблюдаются как признаки профессиональных деструкций, так и те изменения, которые можно рассматривать как личностные ресурсы преодоления деформаций. Противодействовать деструкциям позволяют: установки на качественное выполнение своих обязанностей, готовность дистанцироваться от работы и переключаться от служебных проблем, ориентация на социально одобряемые стратегии поведения и на социальную поддержку со стороны близких и коллег, ценность активной деятельной жизни.
\end{abstract}

\section{PROFESSIONAL TRANSFORMATIONS OF DETENTION CENTERS OFFICERS}

\section{Elena L. Trofimova}

Baikal State University, Irkutsk, Russian Federation

\section{ARTICLE INFO}

Received

September 14, 2016

Accepted

October 28, 2016

Available online

December 28, 2016

\section{KEYWORDS}

Professional transformations, professional deformations, burnout, personal resources of professional deformations

\begin{abstract}
Correctional system executes very important functions as law enforcement force of the country and imposes advanced requirements on its officers. Conditions of professional activity are fair factors of development of professional deformations. Simultaneously with the process of professional activity a person develops variables that decrease negative influence of the activity. The article proves necessity of the term "professional deformations» that are all personal alterations in the process of a person's professional activity. The article studies personal alterations of detention centers officers such as value system, behavioral model or professional activity dynamics alterations. The objects of the study are correctional system officers with service records of: from 1 to 3 years, from 4 to 7 years, and more than 8 years. For the purposes of the study a complex of standard psychognostic procedures was used. Results of the study show development of professional destructions as an outcome of professional activity as well as development of personal resources aimed on negotiation of such deformations. These resources appear to be orientation on proper discharge of professional functions, Capability of a person to disassociate himself/herself from work-related problems, orientation on socially acceptable behavioral strategies, social support of colleagues and relatives, and importance of active strenuous life.
\end{abstract}


В процессе профессионального становления происходят разноплановые личностные изменения. Так Т. В. Зеер трактует «профессиональное становление» как формообразование личности, адекватное требованиям профессиональной деятельности [1, с. 51]. Личность входит в новую систему социальных связей, приобретает профессиональный опыт, прослеживается преобразование сложившихся установок, ориентаций, мотивов поведения, формируются и развиваются профессионально значимые качества, повышается самооценка, стрессоустойчивость.

Происходящие перемены могут носить и негативный характер, наиболее широко в психологической отечественной и зарубежной литературе исследуются эмоциональное выгорание, трактуемое как состояние физического, эмоционального, умственного истощения, как выработанный личностью механизм психологической защиты в форме полного или частичного исключения эмоций (В. В. Бойко, 1996) или «неблагоприятная реакция на рабочие стрессы» (Н. Е. Водопьянова, Е. С. Старченкова, 2005), изучаются в целом профессиональные деструкции как «постепенно накопившиеся изменения сложившейся структуры деятельности и личности, негативно сказывающиеся на продуктивности труда и взаимодействии с другими участниками этого процесса, а также на развитии самой личности» [2-6].

Учитывая конструктивную и деструктивную направленность перемен, целесообразно рассматривать их в совокупности как профессиональные трансформации, понимая под ними любые личностные изменения, происходящие с человеком в процессе его профессиональной деятельности.

Трансформация, например, в толковом словаре Ушакова трактуется как перемена вида, формы чего-нибудь, преобразование, превращение. В философии под трансформацией понимается превращение, преобразование. Заметим, что здесь не говорится о направленности преобразований (в лучшую или худшую сторону), а имеется в виду, что происходит переход от одного состояния к другому.

В психологической науке трансформация личности и классификация трансформационных процессов раскрыта М. Ш. МагометЭминовым, трансформацию личности как многоаспектную проблему рассматривают В. А. Урываев, Б. В. Бойчук, в диссертационном исследовании Е. А. Ковалевой анализируются психологические трансформации личности в пенсионном возрасте и др. [7-9].

Специфика профессиональной деятельности сотрудников пенитенциарных учреждений, отношения с осужденными, виды воспитательных работ, которые проводит сотрудник, предопределяют требования и ограничения профессиональной роли служащего уголовно-исполнительной системы. В качестве факторов риска рассматриваются: общение с людьми, нарушившими закон; особая социальная значимость деятельности; понимание, что каждое действие сотрудника влечет за собой серьезные правовые последствия; необходимость сохранение служебной тайны и др. [10-12].

Целью исследования стало выявление профессиональных трансформаций сотрудников пенитенциарных учреждений.

Объект - профессиональные трансформации.

Предмет исследования - профессиональные трансформации сотрудников пенитенциарных учреждений.

Гипотезами исследования выступили следующие предположения:

1. В процессе профессиональной деятельности наблюдаются профессиональные трансформации, которые могут носить как положительный, так и отрицательный характер.

2. У сотрудников пенитенциарных учреждений с увеличением трудового стажа проявляются признаки профессиональных деформаций, а также наблюдаются позитивные личностные изменения, причем с увеличением стажа службы соотношение положительных и отрицательных трансформаций меняется.

3. Позитивные изменения, происходящие в процессе профессиональной деятельности сотрудников можно рассматривать как личностные ресурсы преодоления деформаций.

В исследовании приняло участие 70 сотрудников УИС, средний возраст 28,9 лет $^{1}$. В зависимости от стажа работы было сформировано 3 выборки испытуемых: 1 группа - сотрудники со стажем работы до 3 лет, 2 группа - стаж свыше 3-х и до 7 лет - именно на этом этапе наблюдаются личностные изменения, обусловленные службой, 3 группа - стаж от 8 лет и выше.

${ }^{1}$ Опрос сотрудников проводился выпускницей специальности «Психология» В. О. Калининой. 
В качестве методов исследования применялись: опросник поведения и переживания, связанного с работой -AVEM (У. Шааршмидт и А. Фишер адаптированный под руководством Т. И. Ронгинской), оценка профессиональной дезадаптации О. Н. Родниной, методика «Ценностные ориентации» М. Рокича, опросник SACS - «стратегии преодоления стрессовых ситуаций» С. Хобфолла, Опросник на выгорание (MBI) К. Маслач и С. Джексон в адаптации Н.Е. Водопьяновой, опросник агрессивности А. Басса и А. Дарки.

Обсуждение результатов. Особенности профессионального поведения сотрудников представлены в табл. 1 и 2.

Анализ полученных данных показывает, что наблюдаются изменения профессиональной активности: снижается уровень профессиональных притязаний - различия достоверны между всеми выделенными по стажу группами $(0,01<p<0,05) ;$ к 4 году службы снижается значимость работы, далее заметна тенденция повышения субъективного значения деятельности.

По стратегиям преодоления проблемных ситуаций в профессиональной деятельности значимо повышается склонность к примирению с неудачами, хотя показатели остаются ниже средних значений, а также прослеживается тенденция к снижению уровню стрессоустойчивости.

Достоверные различия между группами по стажу выявлены при оценке эмоционального отношения к работе: снижается удовлетворенность своими профессиональными достижениями, жизненная удовлетворенность и чувство социального благополучия.

В то же время, в диапазоне выше средних значений остаются стремление качественно выполнять свои обязанности и способность сохранять дистанцию по отношению к работе.

В табл. 3 отражены доминирующие копинг-стратегии сотрудников.

СВодные результаты по методике АVЕМ

\begin{tabular}{|c|c|c|c|c|c|}
\hline $\begin{array}{c}\text { № } \\
\text { п/ா }\end{array}$ & Шкалы & \begin{tabular}{c|} 
Средние \\
значения*
\end{tabular} & 1 (до 3) & 2 (от 4 до 7) & 3 (от 8) \\
\hline 1 & ВА - Субъективное значение деятельности & 5,12 & 5,5 & 4,85 & 5,53 \\
\hline 2 & ВE - Профессиональные притязания & 6,36 & 7,5 & 6,64 & 5,4 \\
\hline 3 & VB - Готовность к энергетическим затратам & 5,39 & 5,6 & 6 & 5,23 \\
\hline 4 & PS - Стремление к совершенству & 4,88 & 5,5 & 5,4 & 5,3 \\
\hline 5 & $\begin{array}{l}\text { DF - Способность к поддержанию дистанции по отношению } \\
\text { к работе }\end{array}$ & 5,48 & 6,75 & 6 & 6,07 \\
\hline 6 & RT - Тенденция к отказу в ситуации неудачи & 5,60 & 2,5 & 3,78 & 3,3 \\
\hline 7 & ОР - Активная стратегия решения проблем & 4,20 & 4,8 & 4,9 & 3,7 \\
\hline 8 & IR - Внутреннее спокойствие и равновесие & 4,65 & 4,75 & 4,64 & 4,4 \\
\hline 9 & ЕE - Чувство успешности в профессиональной деятельности & 3,88 & 3,6 & 3,07 & 2,7 \\
\hline 10 & LZ - Удовлетворенность жизнью & 4,52 & 5,6 & 4,5 & 4 \\
\hline 11 & SU - Чувство социальной поддержки & 5,17 & 5,1 & 4,64 & 4,07 \\
\hline
\end{tabular}

Таблица 2

AVEM результаты расчетов по Т-тесту Стъюдента

\begin{tabular}{|c|c|c|c|c|}
\hline Группа & $t$ & $d f$ & Sig. (2-tailed) & MeanDifference \\
\hline \multicolumn{5}{|l|}{1 и 2} \\
\hline ВE - Профессиональные притязания & 2,454 & 41,498 & 0,018 & 0,8571 \\
\hline RT - Тенденция к отказу в ситуации неудачи & $-2,420$ & 42 & 020 & $-1,2857$ \\
\hline LZ - Удовлетворенность жизнью & 2,022 & 27,965 & 050 & 1,1250 \\
\hline \multicolumn{5}{|l|}{1 и 3} \\
\hline ВE - Профессиональные притязания & 4,364 & 40 & 0,000 & 2,0385 \\
\hline ОР - Активная стратегия решения проблем & 2,755 & 38,826 & 0,009 & 1,1058 \\
\hline LZ - Удовлетворенность жизнью & 2,900 & 28,288 & 0,007 & 1,6250 \\
\hline SU - Чувство социальной поддержки & 2,717 & 32,433 & 0,010 & 1,0481 \\
\hline \multicolumn{5}{|l|}{2 и 3} \\
\hline ВE - Профессиональные притязания & 2,735 & 48,544 & 0,009 & 1,1813 \\
\hline OP - Активная стратегия решения проблем & 2,975 & 52 & 0,004 & 1,1593 \\
\hline
\end{tabular}


Преобладающими стратегиями в 3-х группах являются социально одобряемые действия: вступление в социальный контакт, поиск социальной поддержки, ассертивные и осторожные действия. Со стажем стремление получить социальную поддержку со стороны близких и коллег становится все более актуальным, показатели асоциальных и агрессивных действий приближаются к диапазону низких значений. Как менее используемые стратегии отмечаются и манипулятивные и осторожные модели поведения.

Оценка профессиональной дезадаптации (табл. 4) показала, что в целом по всей выборке сохраняется низкий уровень проявления дезадаптационных симптомов.

Самые низкие значения в 1-й группе респондентов, а наиболее высокие оценки продемонстрировали сотрудники 2-й группы со стажем от 4 до 7 лет: чаще фиксируются нарушения памяти и внимания, снижается общая активность, нарастает усталость, появляются признаки соматовегетативных нарушений (различия с 1-й группой достоверны при $p<0,01)$. Опытные служащие используют личностные ресурсы противодействия дезадаптации, о чем свидетельствует общая тенденция снижения показателей (кроме нарушения сна) у сотрудников со стажем свыше 8 лет.

Анализ данных по методике «Ценностные ориентации» Рокича позволяет утверждать, что:

1. У респондентов всех групп первые позиции среди терминальных занимает ценность стремление к здоровью, приоритетными являются стремления к счастливой семейной жизни и любви.

2. Последнее ранговое место во всех группах занимает ценность «творчество», а также самыми незначимыми оказались ценности: «счастье других», «развлечения», «красота природы и искусства».

3. С повышением стажа работы возрастает значение активной деятельной жизни, материально-обеспеченной жизни, уверенности в себе, а уменьшается значение общественного признания, продуктивной жизни, развития.

4. Среди инструментальных ценностей самые значимые: воспитанность, аккуратность, жизнерадостность.

5. С повышением стажа работы возрастает предпочтение независимости, исполнительности, непримиримости к недостаткам, рационализму, широте взглядов, а понижается ранг ответственности и эффективности в делах.

Таблица 3

Сводные результаты по методике SACS (стратегии преодоления стрессовых ситуаций)

\begin{tabular}{|c|c|c|c|c|c|c|c|}
\hline \multirow{2}{*}{$\begin{array}{c}\text { № } \\
\Pi / \Pi\end{array}$} & \multirow[t]{2}{*}{ Шкала } & \multicolumn{2}{|c|}{1 (до 3) } & \multicolumn{2}{|c|}{2 (от 4 до 7) } & \multicolumn{2}{|c|}{3 (от 8) } \\
\hline & & Среднее & Ранг & Среднее & Ранг & Среднее & Ранг \\
\hline 1 & Ассертивные действия & $23,6^{*}$ & 2 & $20,9^{*}$ & 4 & $19 *$ & 4 \\
\hline 2 & Вступление в социальный контакт & 24,1 & 1 & 23,9 & 1 & 23,1 & 2 \\
\hline 3 & Поиск социальной поддержки & 23,1 & 3 & 23,2 & 2 & 23,5 & 1 \\
\hline 4 & Осторожные действия & 22,6 & 4 & $22,07^{*}$ & 3 & $19,9^{*}$ & 3 \\
\hline 5 & Импульсивные действия & 18,4 & 7 & 17,2 & 7 & 18,4 & 6 \\
\hline 6 & Избегание & 16,75 & 9 & 15,5 & 8 & 17 & 7 \\
\hline 7 & Непрямые действия & $22^{*}$ & 5 & 19,5 & 5 & $18,9^{*}$ & 5 \\
\hline 8 & Асоциальные действия & $19,9^{*}$ & 6 & $17,8^{*}$ & 6 & $15,1^{*}$ & 8 \\
\hline 9 & Агрессивные действия & $18,3^{*}$ & 8 & $14,07^{*}$ & 9 & $14^{*}$ & 9 \\
\hline
\end{tabular}

* Стратегии, значимо отличающиеся у сотрудников по критерию $t$-Стьюдента $(0,01<p<0,05)$.

Таблица 4

Сводные результаты по методике профессиональной дезадаптации

\begin{tabular}{|c|l|r|r|r|}
\hline $\mathbf{1}$ № п/п Шкала & \multicolumn{1}{|c|}{$\mathbf{1}$ (до 3) } & 2 (от 4 до 7) & $\mathbf{3 ~ ( о т ~ 8 ) ~}$ \\
\hline 1 & Эмоциональные сдвиги & 1,00 & 2,50 & 1,53 \\
\hline 2 & Особенности отдельных психических процессов & 0,87 & 1,78 & 0,84 \\
\hline 3 & Снижение общей активности & 0,75 & 3,21 & 2,46 \\
\hline 4 & Ощущение усталости & 0,87 & 2,92 & 1,92 \\
\hline 5 & Соматовегетативные нарушения & 1,31 & 6,35 & 5,30 \\
\hline 6 & Нарушение цикла «сон - бодрствование» & 1,62 & 3,14 & 3,53 \\
\hline 7 & Особенности социального взаимодействия & 2,00 & 3,50 & 2,90 \\
\hline 8 & Снижение мотивации к деятельности & 2,18 & 3,35 & 3,00 \\
\hline \multicolumn{2}{|l|}{ Сумма } & $\mathbf{1 0 , 6 2 5}$ & $\mathbf{2 6 , 7 8 5 ~ 7 1}$ & $\mathbf{2 1 , 5 3 8 4 6}$ \\
\hline
\end{tabular}


Результаты ответов испытуемых по методике «МВI» представлены в табл. 5.

Таблица 5

Сводные результаты по методике МВI

\begin{tabular}{|c|l|r|r|r|}
\hline $\begin{array}{c}\text { № } \\
\text { п/п }\end{array}$ & \multicolumn{1}{|c|}{ Шкала } & $\mathbf{1}$ (до 3) & $\begin{array}{c}\text { 2 } \\
\text { (от 4 до 7) }\end{array}$ & 3 (от 8) \\
\hline 1 & $\begin{array}{l}\text { Эмоциональное } \\
\text { истощение }\end{array}$ & 13,2 & 15,8 & 19,1 \\
\hline 2 & Деперсонализация & 6,1 & 6,5 & 8,5 \\
\hline 3 & $\begin{array}{l}\text { Редукция личных } \\
\text { достижений }\end{array}$ & 36,8 & 29,4 & 31,5 \\
\hline
\end{tabular}

Показатели сотрудников 1-й группы находятся в диапазоне низких значений. Достоверные различия (при $p<0,01)$ обнаружены по всем шкалам между первой и второй группой, после 3-х лет службы начинает снижаться эмоциональный тонус, появляются признаки деперсонализации, редукция значимости собственных достижений, негативное оценивание себя достигает уровня высоких показателей (менее 30). С увеличение стажа тенденции выгорания продолжают нарастать, по шкале редукции личных достижений сохраняется значения близкие к высоким.

Эмоциональное истощение, проявляющееся у сотрудников с высоким стажем работы, не является неожиданностью, так как данная профессия в соответствии с наработками зарубежных и российских психологов относится к профессиям подверженным эмоциональному выгоранию и профессиональным деформациям [12-19].

Такие формы проявления агрессивных реакций как негативизм, вербальная и физическая агрессия именно у молодых служащих диагностируются на уровне выше среднего (табл. 6).

Таблица 6

Сводные результаты по методике Басса-Дарки

\begin{tabular}{|c|l|r|r|r|}
\hline $\begin{array}{r}\text { № } \\
\text { п/п }\end{array}$ & \multicolumn{1}{|c|}{ Шкала } & $\mathbf{1}$ (до 3) & $\begin{array}{c}\mathbf{2} \\
\text { (от 4 до 7) }\end{array}$ & 3 (от 8) \\
\hline 1 & Негативизм & 2,00 & 1,30 & 1,26 \\
\hline 2 & Вербальная агрессия & 8,00 & 6,50 & 6,07 \\
\hline 3 & Косвенная агрессия & 2,60 & 2,07 & 2,10 \\
\hline 4 & Физическая агрессия & 6,25 & 5,20 & 5,20 \\
\hline \multicolumn{2}{|c|}{ Сумма } & $\mathbf{1 8 , 8 0}$ & $\mathbf{1 5 , 2}$ & $\mathbf{1 4 , 6}$ \\
\hline
\end{tabular}

Со стажем наблюдается снижение уровня агрессивности (различия достоверны между 1-й и 2-й , 1-й и 3-й группами), хотя и после 3-х и после 7 лет службы показатели вербальной и физической агрессии сохраняют позиции чуть выше средних.
Таким образом, полученные в результате исследования данные позволят сделать следующие выводы:

1. У сотрудников пенитенциарных учреждений с увеличением трудового стажа проявляются такие признаки профессиональных деформаций как:

- снижается уровень профессиональных притязаний, удовлетворенность своими профессиональными достижениями, жизненная удовлетворенность и чувство социального благополучия;

- появляются признаки соматовегетативных нарушений, нарушение цикла «сон - бодрствование», снижается общая активность, диагностируются признаки эмоционального истощения;

- происходит трансформация ценностей: уменьшается значение общественного признания, продуктивной жизни, развития, понижается ранг ответственности и эффективности в делах;

- реже в стрессовых ситуациях прибегают к ассертативным и осторожным действиям.

2. У сотрудников пенитенциарных учреждений с увеличением трудового стажа выявлены позитивные изменения:

- на уровне выше средних значений сохраняется стремление качественно выполнять свои обязанности;

- готовность дистанцироваться от работы и возрастание тенденции к примирению с неудачами дает возможность переключаться от служебных проблем;

- более важной становится социальная поддержка со стороны близких и коллег;

- наблюдается снижение уровня агрессивности, показатели асоциальных и агрессивных действий приближаются к диапазону низких значений;

- на уровне жизненных ценностей возрастает значение активной деятельной жизни, материально-обеспеченной жизни, уверенности в себе, отдаётся предпочтение независимости, исполнительности, рационализму, широте взглядов.

3. Наиболее ярко симптоматика профессиональных деформаций проявляется у сотрудников со стажем от 3-х лет службы, у служащих свыше 8 лет более выраженными становятся положительные трансформации.

4. Позитивные изменения, происходящие в процессе профессиональной деятельности сотрудников можно рассматривать как ресурсы преодоления деформаций. 


\section{Список использованной литературы}

1. Зеер Э. Ф. Профессиональное становление личности инженера-педагога / Э. Ф. Зеер. Свердловск : Изд-во Урал. ун-та, 1988. - 189 с.

2. Зеер Э. Ф. Психология профессий / Э. Ф. Зеер. - М. : Акад. проект : Фонд «Мир», 2008. - 257c.

3. Бойко В. В. Синдром «эмоционального выгорания» в профессиональном общении / В. В. Бойко. - СПб. : Питер, 2005. - 105 с.

4. Водопьянова Н. Е. Синдром выгорания: диагностика и профилактика / Н. Е. Водопьянова, Е. С. Старченкова. - СПб. : Изд-во С.-Петерб. гос. ун-та, 2005. - 336 с.

5. Марчукова С. Ф. Формирование эмоциональной компетенции сотрудников пенитенциарной системы / С. Ф. Марчукова // Актуальные проблемы уголовного и уголовно-исполнительного права : материалы Междунар. заоч. науч.-практ. конф., 2009 г. Новокузнецк : Кузбас. ин-т ФСИН России, 2009. - С. 31-35.

6. Maslach C. The measurement of experienced burnout / C. Maslach, Susan E. Jackson // Journal of Occupational Behaviour. - 1981. - Vol. 2. - P. 99-113.

7. Магомед-Эминов М. Ш. Деятельностно-смысловой подход к психологической трансформации личности : автореф. дис. ... Д-ра психол. наук : 19.00.01 / М. Ш. Магомед. - М., 2009. - 53 c.

8. Ковалева Е. А. Психологические трансформации личности в пенсионном возрасте : дис. ... канд. психол. наук : 19.00.01 / Е. А. Ковалева. - Сочи, 2010. - 185 с.

9. Урываев В. А. Трансформации личности как многоаспектная проблема [Электронный ресурс] / В. А. Урываев, Б. В. Бойчук // Клиническая и медицинская психология: исследования, обучение, практика. - 2013. - № 2 (2). - Режим доступа: http://medpsy. $\mathrm{ru} / \mathrm{climp}$.

10. Трофимова Е. Л. Стереотипы восприятия сотрудников правоохранительных органов населением Иркутской области / Е. Л. Трофимова / / Известия Иркутской государственной экономической академии. - 2014. - № 3 (95). - С. 112-120.

11. Фонталова Н. С. Стресс в профессиональной деятельности и его психологоэкономические последствия / Н. С. Фонталова // Известия Иркутской государственной экономической академии. - 2011. - № 3 (77). - С. 179-182.

12. Шабанова К. Г. Специфика «эмоционального выгорания» у сотрудников линейных подразделений / К. Г. Шабанова // Психопедагогика в правоохранительных органах. 2007. - № 2. - С. 41-45.

13. Ронгинская Т. И. Синдром выгорания в социальных профессиях / Т. И. Ронгинская // Психологический журнал. - 2002. - Т. 23, № 3. - С. 85-95.

14. Лукшина О. Ю. Профессиональная роль и ее значение в развитии симптомов «психического выгорания» пенитенциарных служащих / О. Ю. Лукшина // Прикладная юридическая психология. - 2013. - № 1. - С. 59-65.

15. Кобозев И. Ю. Личностные особенности стресс-преодолевающего поведения бывших сотрудников, осужденных за совершение преступлений коррупционной направленности / И. Ю. Кобозев // Психопедагогика в правоохранительных органах. - 2016. - № 2 (65). C. 26-30.

16. Professional activity motives of private security company employees for sustainable development / S. Guseva, V. Dombrovskis, S. Čapulis, S. Lukash / / Journal of Security and Sustainability Issues. - 2016. - № 6 (1). - P. 145-153.

17. Gender and coping: The dual-axis model of coping / S. E. Hobfoll, C. L. Dunahoo, Y. BenPorath, J. Monnier // American Journal of Community Psychology. - 1994. - Vol. 22 (1). P. 49-82.

18. Teoh W. M.-Y. Factors influencing job burnout among human resource employees / W. M.-Y Teoh, C.-Y. Yau, S.-C. Chong / / Proceeding of International conference on management ICM. - Penang, Malaysia, 2011. - P. 830-841.

19. Zakrizevska M. Occupational Stress and Professional Deformation Among / M. Zakrizevska, J. Bulatova / / Journal of Business Management. - 2015. - Vol. 9. - P. 20-28.

\section{References}

1. Zeer E. F. Professional'noe stanovlenie lichnosti inzhenera-pedagoga [Professional development of teaching engineer's personality]. Sverdlovsk, Ural State University Publ., 1988. 189 p.

2. Zeer E. F. Psikhologiya professii [Professions psychology]. Moscow, Akademicheskii proekt Publ., Fond «Mir», 2008. 257 p.

3. Boiko V. V. Sindrom «emotsional'nogo vygoraniya» v professional'nom obshchenii [«Burnout» syndrome in professional communication]. Saint Petersburg, Piter Publ., 2005. 105 p. 
4. Vodop'yanova N. E., Starchenkova E. S. Sindrom vygoraniya: diagnostika i profilaktika [«Burnout» syndrome: diagnostics and prophylaxis]. Saint Petersburg State University Publ., 2005. 336 p.

5. Marchukova S. F. Formation of emotional competence of penitentiary system officers. Aktual'nye problemy ugolovnogo i ugo-lovno-ispolnitel'nogo prava. Materialy Mezhdunarodnoi zaochnoi nauchno-prakticheskoi konferentsii, $2009 \mathrm{~g}$. [Challenging issues of criminal and penal law. Materials of International Research Conference, 2009]. Novokuznetsk, Kuzbass Univercity of Russian Federal Penitentiary Service Publ., 2009, pp. 31-35. (In Russian).

6. Maslach C., Jackson Susan E. The measurement of experienced burnout. Journal of Occupational Behaviour, 1981, vol. 2, pp. 99-113.

7. Magomed-Eminov M. Sh. Deyatel'nostno-smyslovoi podkhod k psikhologicheskoi transformatsii lichnosti. Avtoref. Dokt. Diss. [Activity-semantic approach to psychologic transformation of a person. Doct. Diss. Thesis]. Moscow, 2009. 53 p.

8. Kovaleva E. A. Psikhologicheskie transformatsii lichnosti v pensionnom vozraste. Kand. Diss. [Psychologic transformations of a person in retirement age. Cand. Diss.]. Sochi, 2010. 185 p.

9. Uryvaev V. A., Boichuk B. V. Transformation of a person as multifold problem. Klinicheskaya $i$ meditsinskaya psikhologiya: issledovaniya, obuchenie, praktika = Clinical and medical Psychology: research, education, practice, 2013, no. 2 (2). Available at: http://medpsy.ru/climp. (In Russian).

10. Trofimova E. L. Stereotypes of perception of employees of law enforcement bodies by the population of Irkutsk region. Izvestiya Irkutskoi gosudarstvennoi ekonomicheskoi akademii = Bulletin of Irkutsk State Economics Academy, 2014, no. 3 (95), pp. 112-120. (In Russian).

11. Fontalova N. S. Stress in professional activity and its psychological and economic consequences Izvestiya Irkutskoi gosudarstvennoi ekonomicheskoi akademii = Bulletin of Irkutsk State Economics Academy, 2011, no. 3 (77), pp. 179-182. (In Russian).

12. Shabanova K. G. Specific nature of «burnout» of maneuver elements officers. Psikhopedagogika v pravookhranitel'nykh organakh $=$ Psychopedagogics in Law Enforcement Agencies, 2007, no. 2, pp. 41-45. (In Russian).

13. Ronginskaya T. I. «Burnout syndrome» in social-related professions. Psikhologicheskii zhurnal $=$ Psychology Journal, 2002, vol. 23, no. 3, pp. 85-95. (In Russian).

14. Lukshina O. Yu. Professional role and its influence on the development of «burnout» symptoms of penitentiary officers. Prikladnaya yuridicheskaya psikhologiya= Applied Legal Psychology, 2013, no. 1, pp. 59-65. (In Russian).

15. Kobozev I. Yu. Personal peculiarities of anti-stress behavior of ex-officers condemned for corruption-related crime. Psikhopedagogika v pravookhranitel'nykh organakh = Psychopedagogics in Law Enforcement Agencies, 2016, no. 2 (65), pp. 26-30. (In Russian).

16. Guseva S., Dombrovskis V., Capulis S., Lukash S. Professional activity motives of private security company employees for sustainable development. Journal of Security and Sustainability Issues, 2016, no. 6 (1), pp. 145-153.

17. Hobfoll S. E., Dunahoo C. L., Ben-Porath Y., Monnier J. Gender and coping: The dual-axis model of coping. American Journal of Community Psychology, 1994, vol. 22 (1), pp. 49-82.

18. Teoh W. M.-Y., Yau C.-Y., Chong S.-C. Factors influencing job burnout among human resource employees. Proceeding of International conference on management ICM. Penang, Malaysia, 2011, pp. 830-841.

19. Zakrizevska M., Bulatova J. Occupational Stress and Professional Deformation Among. Journal of Business Management, 2015, vol. 9, pp. 20-28.

\section{Информация об авторе}

Трофимова Елена Леонидовна - кандидат психологических наук, доцент, кафедра социальной и экономической психологии, социологии и социальной работы, Байкальский государственный университет, 664003, Российская Федерация, г. Иркутск, ул. Ленина, 11, e-mail: trofimova-bgy@mail.ru.

\section{Библиографическое описание статьи}

Трофимова Е. Л. Профессиональные трансформации сотрудников пенитенциарных учреждений / Е. Л. Трофимова / / Психология в экономике и управлении. - 2016. - Т. 8, № 1-2. - С. 36-42. DOI : 10.17150/2225-7845.2016.8(1-2).36-42.

\section{Author info}

Tofimova, Elena L. - PhD in Psychological Sciences, associate professor, Social and Economic Psychology Department, Baikal State University, 11 Lenin St., 664003, Irkutsk, Russian Federation, e-mail: trofimova-bgy@mail.ru.

\section{Reference to article}

Trofimova E. L. Professional transformations of detention centers officers. Psikhologiya v ekonomike $i$ upravlenii $=$ Psychology in Economics and Management, 2016 , vol. 8 , no. $1-2$, pp. $36-42$. DOI: $10.17150 / 2225-$ 7845.2016.8(1-2).36-42. (In Russian). 